\title{
Particle size dependence of biogenic secondary organic aerosol molecular composition
}

\author{
Peijun Tu and Murray V. Johnston \\ Department of Chemistry and Biochemistry, University of Delaware, Newark, Delaware 19716, USA \\ Correspondence to: Murray V. Johnston (mvj@udel.edu)
}

Received: 20 January 2017 - Discussion started: 30 January 2017

Revised: 1 May 2017 - Accepted: 3 May 2017 - Published: 22 June 2017

\begin{abstract}
Formation of secondary organic aerosol (SOA) is initiated by the oxidation of volatile organic compounds (VOCs) in the gas phase whose products subsequently partition to the particle phase. Non-volatile molecules have a negligible evaporation rate and grow particles at their condensation rate. Semi-volatile molecules have a significant evaporation rate and grow particles at a much slower rate than their condensation rate. Particle phase chemistry may enhance particle growth if it transforms partitioned semi-volatile molecules into non-volatile products. In principle, changes in molecular composition as a function of particle size allow non-volatile molecules that have condensed from the gas phase (a surface-limited process) to be distinguished from those produced by particle phase reaction (a volume-limited process). In this work, SOA was produced by $\beta$-pinene ozonolysis in a flow tube reactor. Aerosol exiting the reactor was size-selected with a differential mobility analyzer, and individual particle sizes between 35 and $110 \mathrm{~nm}$ in diameter were characterized by on- and offline mass spectrometry. Both the average oxygen-to-carbon $(\mathrm{O} / \mathrm{C})$ ratio and carbon oxidation state (OSc) were found to decrease with increasing particle size, while the relative signal intensity of oligomers increased with increasing particle size. These results are consistent with oligomer formation primarily in the particle phase (accretion reactions, which become more favored as the volume-to-surface-area ratio of the particle increases). Analysis of a series of polydisperse SOA samples showed similar dependencies: as the mass loading increased (and average volume-to-surface-area ratio increased), the average $\mathrm{O} / \mathrm{C}$ ratio and $\mathrm{OSc}$ decreased, while the relative intensity of oligomer ions increased. The results illustrate the potential impact that particle phase chemistry can have on
\end{abstract}

biogenic SOA formation and the particle size range where this chemistry becomes important.

\section{Introduction}

Ultrafine particles, defined here as smaller than $100 \mathrm{~nm}$ in diameter, constitute the largest number of particles in the atmosphere and are of interest owing to their disproportionate influence on climate and human health (Bzdek et al., 2012; Zhang et al., 2012). Particularly important is their role in formation of cloud condensation nuclei (CCN) and their corresponding impact on radiative forcing (Myhre et al., 2013). For ultrafine particles to grow to a climatically relevant size, the particle growth rate must exceed the loss rate. The greatest uncertainty associated with particle growth and its impact on radiative forcing is the contribution of secondary organic matter (Carslaw et al., 2013), which is formed by oxidation of volatile compounds in the gas phase followed by subsequent migration of the products to the particle phase.

On a global scale, organic aerosol constitutes a substantial fraction of the total aerosol mass in the atmosphere (Hallquist et al., 2009; Jimenez et al., 2009; Kanakidou et al., 2005), and most of this is secondary (Jimenez et al., 2009; Ng et al., 2010). On a molecular level, ambient organic aerosol is very complex, encompassing hundreds to thousands of individual compounds (Chan et al., 2013; Goldstein and Galbally, 2007; Hallquist et al., 2009; Mutzel et al., 2015; Putman et al., 2012). Laboratory secondary organic aerosol (SOA) is similarly complex, and a variety of oxidation and degradation pathways have been proposed to explain the product distributions (Daumit et al., 2013; Hall and Johnston, 2012; Hallquist et al., 2009; Perraud et al., 2012). Part of this complexity 
arises from the formation of high-molecular-weight (MW) oligomeric species from two or more precursor molecules (Kalberer et al., 2004; Tolocka et al., 2004). Oligomers can constitute almost half of the SOA mass in laboratory experiments (Gao et al., 2004; Hall and Johnston, 2011).

The distribution of organic molecules between the gas and particle phases is described by absorptive partitioning theory (Pankow, 1994). When precursor molecules are oxidized in the gas phase, the products partition to the particle phase, causing particle growth. Non-volatile molecules have a negligible evaporation rate once they partition to the particle phase. These molecules cause particle growth at a rate given by their condensation rate from the gas phase. Semivolatile molecules have a substantial evaporation rate and therefore cause particle growth at a rate much slower than their condensation rate. For simplicity, in this work we use the terms "condensation" and "condensational growth" to describe the process by which non-volatile molecules in the gas phase undergo partitioning to cause particle growth at the condensation rate. The recent detection and characterization of extremely low volatility organic compounds (ELVOCs) in the gas phase have uncovered a previously underappreciated pathway for condensational growth (Bianchi et al., 2016; Ehn et al., 2014). For monoterpene oxidation, the range of ELVOC species includes both highly functionalized monomers and oligomers.

The dependence of chemical composition on particle size can provide insight into particle growth mechanisms. Processes limited by the amount of available surface area, such as condensation, are favored in smaller particles, where the surface-to-volume ratio is high. Processes limited by the amount of available volume, such as partitioning, are favored in larger particles, where the surface-to-volume ratio is low. Superimposed on these dependencies is the radiusof-curvature (Kelvin) effect on molecular volatility, which also favors the incorporation of lower-volatility species into smaller-diameter particles. Winkler et al. (2012) have reported size-resolved composition of particles between 10 and $40 \mathrm{~nm}$ in diameter that were produced by $\alpha$-pinene ozonolysis. Based on signal intensities of species detected by thermal desorption chemical ionization mass spectrometry (TDCIMS), $10-20 \mathrm{~nm}$ particles contained a greater fraction of lower-volatility species, while $30-40 \mathrm{~nm}$ particles contained a greater fraction of higher-volatility species. In this experiment, species volatility was qualitatively assessed by the loss of signal intensity due to sample evaporation over time. In a second study of SOA from $\alpha$-pinene ozonolysis, Zhao et al. (2013) used measurements of gas phase molecular species by chemical ionization mass spectrometry to show a positive correlation of higher-MW (and presumably less volatile) species with the number concentration of 10-20 nm particles, whereas lower-MW (and presumably more volatile) species were positively correlated with the number concentration of $30-40 \mathrm{~nm}$ particles. In a third study of SOA from $\alpha$-pinene ozonolysis, Kidd et al. (2014) showed that particles in the
250-500 $\mathrm{nm}$ range contained a greater fraction of oligomers, while particles greater than $500 \mathrm{~nm}$ contained a greater fraction of monomers. Molecular composition measurements by Zhao et al. (2015) of size-selected particles produced by trans-3-hexene ozonolysis showed that particles smaller than $100 \mathrm{~nm}$ contained a greater fraction of high-MW oligomers than particles larger than $100 \mathrm{~nm}$. With the exception of Kidd et al., which focused on much larger particle sizes than the rest, the above experiments are consistent with the concept that higher-MW, lower-volatility species formed in the gas phase are more strongly represented in smaller-diameter particles, as would be expected from a condensation-driven process.

Particle phase chemistry - specifically accretion reactions in the particle phase that form higher-MW, lower-volatility oligomers from higher-volatility, lower-MW monomers (Barsanti and Pankow, 2005) - has been proposed as an additional pathway for SOA formation. Accretion chemistry, which produces non-volatile molecules directly in the particle phase, and ELVOC condensation represent two separate sources for oligomers that are detected in the particle phase. It has been noted that relatively few ELVOC molecular formulas obtained from gas phase measurements match those of oligomers detected in particle phase measurements (Mentel et al., 2015; Tu et al., 2016). This dissimilarity could arise from subsequent reaction of ELVOCs after they enter the particle phase, or by the formation of completely new oligomers in the particle phase through accretion chemistry. In principle, these two sources can be distinguished through the size dependence of particle composition, since molecular species derived from condensation (surface area limited) should be more strongly represented in smaller particles while those derived from accretion chemistry (volume limited) should be more strongly represented in larger particles. A particlesize-dependent molecular composition arising from particle phase reaction was suggested in a modeling study of SOA produced from dodecane photooxidation, though experimental measurements in that work were confined to particle size distributions as a function of reaction time (Shiraiwa et al., 2013).

In the work presented here, we consider the particle-sizedependent chemical composition of SOA produced by $\beta$ pinene ozonolysis. The particles of interest, $30-110 \mathrm{~nm}$ in diameter, are size-selected from a polydisperse aerosol and are large enough that the radius-of-curvature effect of molecular volatility is negligible. Therefore, size-dependent changes in composition reflect the relative importance of surface-arealimited vs. volume-limited processes. In addition, the particles are small enough that phase separation within the particles is unlikely to occur (Veghte et al., 2013). We also consider polydisperse SOA samples having similar volume-tosurface-area ratios to the size-selected samples. The results provide direct evidence for accretion chemistry as a significant source of oligomers in SOA from this precursor. 


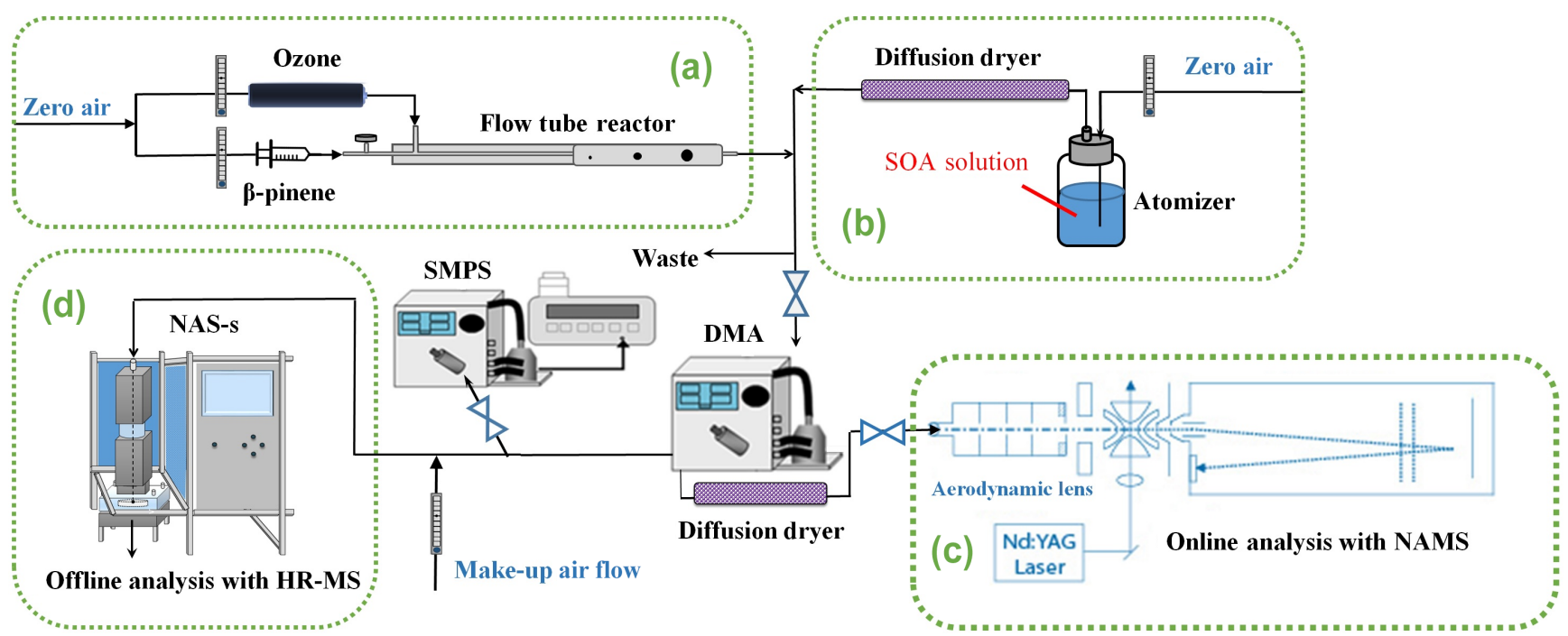

Figure 1. Schematic of the experimental workflow. SOA is produced either directly from the flow tube reactor (a) or re-aerosolization from an atomizer (b). Analysis is performed online by NAMS (c) or offline by HR-MS after sample collection with NAS-s (d).

\section{Experimental section}

\subsection{Aerosol generation and size selection}

Figure 1 shows the experimental setup used in this work. All gas flows were generated from zero air (model 737, Aadco Instruments Inc., Miami, FL, USA) to minimize contamination. SOA was generated in a flow tube reactor (FTR) (Fig. 1a) described previously (Hall et al., 2013; Tu et al., 2016). In most experiments, the concentrations of $\beta$ pinene and ozone after mixing in the reactor were 1 and 10 ppmv, respectively, giving an SOA mass loading of about $2300 \mu \mathrm{g} \mathrm{m}^{-3}$ at the reactor exit. In a separate set of experiments, the SOA mass loading was varied in the 5$2300 \mu \mathrm{g} \mathrm{m}^{-3}$ range by varying the $\beta$-pinene concentration between 0.03 and 1 ppmv. Blank samples were obtained by flowing zero air into FTR to mix with ozone in the absence of $\beta$-pinene. All FTR experiments were performed at a low relative humidity $(8 \%)$ since very little difference was found in the molecular composition of SOA from $\beta$-pinene ozonolysis that was generated with $35-70 \%$ RH vs. conditions used in the current work (Tu et al., 2016). Understanding how relative humidity (as well as other experimental conditions) might quantitatively impact oligomer formation is important to consider in future studies.

In a control experiment, polydisperse SOA from the FTR $\left(2300 \mu \mathrm{g} \mathrm{m}^{-3}\right)$ that had been previously collected onto a filter was extracted into 50-50 acetonitrile/water and atomized (ATM 226, TOPAS, Dresden, Germany) to produce a control aerosol. Figure $1 \mathrm{~b}$ shows the apparatus, which included a diffusion dryer to reduce the amount of water vapor in the aerosol flow. The goal of this experiment was to generate SOA-like aerosol that did not have a particle-sizedependent chemical composition associated with it, though the composition of this aerosol was not expected to be precisely the same as the original collected SOA because of possible chemical reactions prior to and/or during atomization. This experiment also provided the opportunity to assess possible artifacts due to sample collection and analysis after size selection (see Sect. 2.2). The particle size distribution of the control aerosol was fine-tuned by varying the gas flow conditions into the atomizer and the concentration of extracted SOA in the solution used for atomization (Stabile et al., 2013), so that a sufficient aerosol mass concentration was obtained at each mobility diameter of interest $(35,60$, $85,110 \mathrm{~nm}$ ) to permit chemical analysis. Sample blanks for the control experiment were obtained by atomizing pure solvent (Park et al., 2012).

Particle size distributions were monitored with a scanning mobility particle sizer (SMPS, TSI Incorporated, St. Paul, Minnesota, USA). Specific particle sizes within the size distribution were selected with a separate differential mobility analyzer (DMA, model 3081, TSI Incorporated, St. Paul, Minnesota, USA). The mobility diameters studied in this work were $35,60,85$, and $110 \mathrm{~nm}$. Size distributions are shown in Fig. S1 in the Supplement. Mass concentrations are given in Table S1 in the Supplement. Because of the low mass concentrations after size selection, zero air was sent through the entire experimental apparatus for $12 \mathrm{~h}$ after each experiment to remove contamination.

\subsection{Sample collection and offline analysis with high-resolution mass spectrometry (HR-MS)}

Particles were collected with a nano-aerosol sampler operating in the spot collection mode (NAS-s; in Fig. 1d). The sampler was custom designed and built by Aerosol Dynamics, Inc. (Berkeley, California, USA). This device uses a water- 
based condensation method (Hering and Stolzenburg, 2005) to either sample particles into a small spot in a collection well or concentrate them into an outlet flow aerosol flow. When used in spot mode, particles deposited in the collection well were able to be dissolved in a minimum amount of solvent for subsequent offline analysis. In this device, aerosol first passed through a "conditioner" region at $5^{\circ} \mathrm{C}$, followed by a heated "initiator" region at $35^{\circ} \mathrm{C}$ where the aerosol became saturated with water vapor. The aerosol then entered a cooled "moderator" region at $10^{\circ} \mathrm{C}$ where the temperature decrease created a supersaturated vapor. In this region, water condensed on the particles to produce droplets, which were subsequently focused to a $\sim 1 \mathrm{~mm}$ spot in a collection well. The well was heated to $35^{\circ} \mathrm{C}$ to evaporate the condensed water (dry deposition mode) from collected particles. After a sufficient amount of sample was collected $(\sim 10 \mu \mathrm{g}$ in these experiments), acetonitrile/deionized water $(1: 1)$ solvent was added to the well to dissolve the collected particles to a concentration of $0.1 \mathrm{mg} \mathrm{mL}^{-1}$ for offline analysis. Depending on aerosol mass concentration, $<1$ to $\sim 34 \mathrm{~h}$ hours were required to collect a sufficient amount of sample, though one specific control sample required $93 \mathrm{~h}$ (see Table S1). Mass spectra of polydisperse SOA were similar for samples collected with NAS-c at $35^{\circ} \mathrm{C}$ vs. a standard filter at room temperature, confirming that gentle heating inside the NAS-c did not cause thermal decomposition of this aerosol. NAS-c had the advantage over filter collection of being able to work with smaller sample sizes and therefore shorter collection times.

Offline molecular characterization was performed by HRMS with a Q Exactive ${ }^{\mathrm{TM}}$ Hybrid Quadrupole-Orbitrap Mass Spectrometer (Thermo Scientific, Waltham, Massachusetts, USA) coupled to a heated-electrospray ionization (HESI) probe. For these measurements, the sample flow rate was $3 \mu \mathrm{L} \mathrm{min}^{-1}$ with an injection volume of $10 \mu \mathrm{L}$. Other operating parameters included spray voltage $(2.5-3.5 \mathrm{kV})$ and capillary temperature $\left(250-275^{\circ} \mathrm{C}\right)$. The possibility of producing artifacts of non-covalently bound clusters was ruled out using the approach discussed elsewhere (Hall et al., 2013; $\mathrm{Tu}$ et al., 2016). Full MS scans were acquired over the range $100-1000 \mathrm{~m} / \mathrm{z}$ with a mass resolving power of 70000 . Each spectrum was obtained by averaging $\sim 130$ scans over a period of approximately $1.0 \mathrm{~min}$ and then processed with Xcalibur $^{\mathrm{TM}}$ software.

Five replicate samples were analyzed for each experiment, and molecular formulas had to be positively detected and assigned in all five replicates in order to be considered further. Blank sample subtraction was performed for each sample prior to the data analysis. Data analysis was performed as described previously, targeting closed-shell molecular formulas (Tu et al., 2016). We also performed Kendrick mass defect analysis (Herzsprung et al., 2014; Phungsai et al., 2016) and calculated the RDB-O value (ring and double-bond equivalent of each molecular formula minus the number of oxygen atoms in the formula; the maximum RDB-O distribution resides within the range -10 and 10 for hydrophobic
CHO species; Herzsprung et al., 2014) as the updated criteria to help filter the unreasonable assigned formulas. After removing background peaks, unreasonable formulas, and redundancies due to isotopic substitution, hundreds of unique molecular formulas remained for each sample. The number of common molecular formulas detected and assigned in all five replicates for each experiment is given in Table S2 along with the mass- and intensity-weighted average oxygen-tocarbon $(\mathrm{O} / \mathrm{C})$ ratios of these formulas. This table also highlights the inherent variability among replicates that arises from low intensity peaks near the detection limit.

\subsection{Online analysis with NAMS}

Online single-particle analysis was performed with a modified nano-aerosol mass spectrometer (NAMS), shown in Fig. 1c. The previously reported NAMS configuration for analysis of $10-30 \mathrm{~nm}$ diameter particles (Pennington and Johnston, 2012; Wang and Johnston, 2006; Wang et al., 2006) was modified to enable analysis of particles between 40 and $110 \mathrm{~nm}$ in diameter. Particles entered the mass spectrometer through an aerodynamic lens assembly that focused particles into a tight beam in the ion source region. A focused, high-energy pulsed laser beam $(532 \mathrm{~nm}, 5 \mathrm{~Hz}$, $230 \mathrm{~mJ}_{\text {pulse }}{ }^{-1}$ focused to an effective spot size of about $0.1 \mathrm{~mm}$ diameter) intercepted the particle beam. When a particle was in the beam path when the laser fired, a plasma was formed that quantitatively disintegrated the particle into multiply charged atomic ions, whose relative signal intensities gave the elemental composition of the particle (Klems and Johnston, 2013; Zordan et al., 2010). Aerosol mass spectra were obtained by averaging $\sim 200$ individual particle spectra, and the process of obtaining an average mass spectrum was repeated three times over the course of each experiment, which provided confirmation that particle composition did not change during an experiment. Figure S2 gives an example mass spectrum of size-selected $60 \mathrm{~nm}$ SOA particles. Table $\mathrm{S} 3$ summarizes the elemental composition data from the various experiments.

\section{Results and discussion}

\subsection{Elemental composition of size-selected SOA}

NAMS measurements provided the opportunity to determine the bulk elemental composition of size-selected SOA, specifically the $\mathrm{O} / \mathrm{C}$ ratio. $\mathrm{O} / \mathrm{C}$ ratios as a function of particle size are summarized in Table S3 and shown in Fig. 2a. The trend of decreasing $\mathrm{O} / \mathrm{C}$ ratio with increasing particle size is consistent with the expectation that lower-volatility (and more highly functionalized) molecules are preferentially found in small particles, where the high surface-tovolume ratio favors condensation of non-volatile molecules over partitioning of semi-volatile molecules, while highervolatility (and less functionalized) molecules are preferen- 

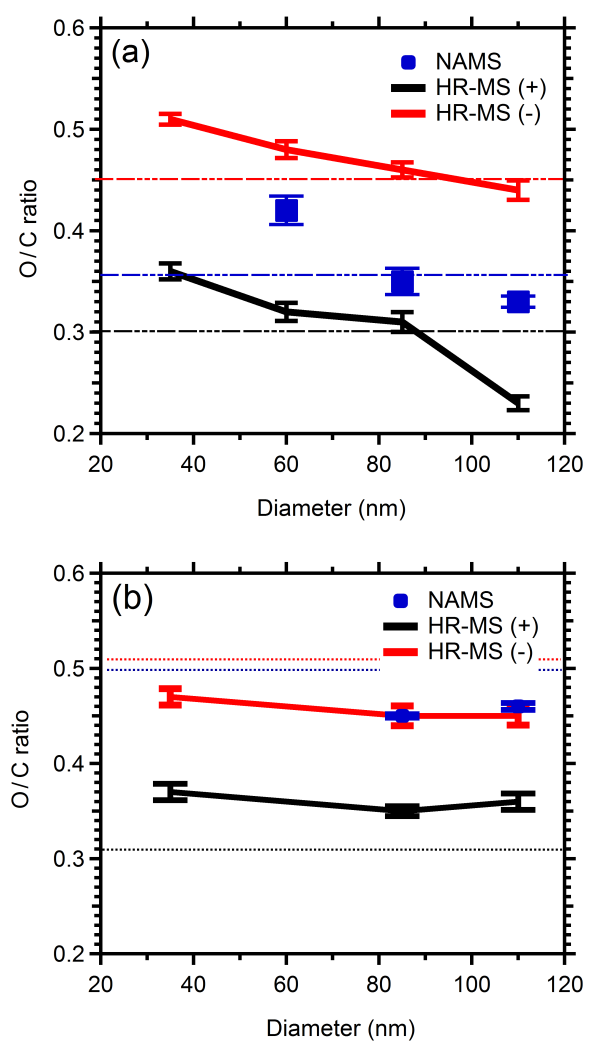

Figure 2. Average O / C ratio vs. particle diameter for SOA (a) generated from the flow tube reactor and (b) re-aerosolized from the atomizer. Dashed lines in the plots give the $\mathrm{O} / \mathrm{C}$ ratios of the corresponding polydisperse SOA samples. Blue markers represent data obtained by NAMS. Black (positive-ion mode) and red (negativeion mode) markers represent data obtained by HR-MS. Error bars represent 1 standard deviation for the five replicate experiments.

tially found in large particles, where the lower surface-tovolume ratio favors partitioning of semi-volatile molecules to a greater degree. This same general trend was found for molecular analysis, as shown in Fig. 2a by the mass- and intensity-weighted O / C ratios (Hall et al., 2013) averaged over all assigned molecular formulas. For both positive and negative molecular ions, the average $\mathrm{O} / \mathrm{C}$ ratio was also found to decrease with increasing particle size. The average $\mathrm{O} / \mathrm{C}$ ratios obtained from negative ions were much greater than those from positive ions, which reflects the bias of negative-ion detection toward molecules containing acid groups, whereas positive-ion detection is biased toward detection of molecules containing carbonyls only (Hall et al., 2013). The $\mathrm{O} / \mathrm{C}$ ratios obtained from NAMS lie between the positive and negative mode $\mathrm{O} / \mathrm{C}$ ratios obtained from HR-MS, which is reasonable since the NAMS measurements represent all molecular species in the sample.

The similarity of the NAMS and HR-MS data in Fig. 2a suggests that these size dependencies are not artifacts of the respective measurement methods. To provide further confir- mation, the control aerosol was analyzed by the same procedure. The results are summarized in Table S3 and shown in Fig. 2b. As expected, no particle size dependence is observed in either the NAMS or HR-MS data.

\subsection{Molecular composition of size-selected SOA}

To provide context for the particle-size-dependent changes in molecular composition discussed below, it is helpful to consider the gas phase products of $\beta$-pinene ozonolysis and their relevance to chemical processes that drive particle growth. Gas phase products were not measured in this study but have been the subject of several previous investigations. Aerosol yields for $\beta$-pinene ozonolysis under conditions similar to the experiments performed here have been reported to be on the order of $30 \%$, with products spanning a wide range of volatilities (von Hessberg et al., 2009). First and foremost with regard to particle formation in an unseeded experiment is the production of ELVOCs, which for monoterpene ozonolysis (Ehn et al., 2014) include molecular formulas spanning monomers (for the purpose of this study defined as molecules having fewer than 9 carbon atoms since $\beta$-pinene ozonolysis results in the loss of a carbon atom) and dimers (defined here as molecules having between 10 and 18 carbon atoms). Monomer ELVOCs necessarily are highly oxidized since this is needed to achieve very low volatility, whereas dimers can be somewhat less oxidized owing to their larger molecular size. ELVOCs corresponding to higher-order oligomers (defined here as molecules having greater than 18 carbon atoms) are exceedingly rare, which is not surprising since the probability of gas phase reaction decreases quickly with increasing number of precursor molecules. ELVOCs are inefficiently produced from $\beta$ pinene ozonolysis owing to its exocyclic double bond, with an estimated yield less than $0.1 \%$ (Ehn et al., 2014). Most products of $\beta$-pinene ozonolysis are volatile, or semi-volatile monomers partition between the gas and particle phases (Jaoui and Kamens, 2003).

Molecular level changes in particle composition are summarized in Figs. 3 and 4, which compare the mass spectra and corresponding molecular products, respectively, for both positive- and negative-ion mass analysis of size-selected SOA at 35 and $110 \mathrm{~nm}$. These changes are interpreted on the basis of monomers (which encompass both ELVOCs that condense and semi-volatile products that partition), dimers (which encompass both ELVOCs that condense and products of accretion chemistry that are produced directly in the particle phase), and higher-order oligomers (produced almost exclusively by accretion chemistry in the particle phase).

Figure 4 shows plots of average carbon oxidation state $(\mathrm{OSc})$ vs. number of carbon atoms for all assigned molecular formulas, color-coded to indicate formulas that are unique to $35 \mathrm{~nm}$ particles, unique to 110 particles, and common to both particle sizes. OSc for a molecular formula is 


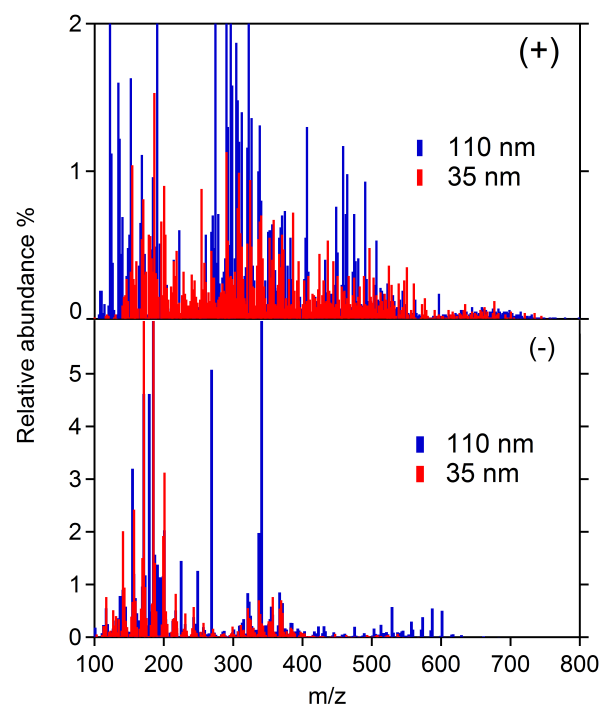

Figure 3. Positive (+) and negative (-) ion mass spectra of $35 \mathrm{~nm}$ (red) and $110 \mathrm{~nm}$ (blue) monodisperse SOA samples averaged over the five replicate experiments.

defined as (Kroll et al., 2011)

$\mathrm{OSc}=2 \mathrm{O} / \mathrm{C}-\mathrm{H} / \mathrm{C}$,

where $\mathrm{O} / \mathrm{C}$ and $\mathrm{H} / \mathrm{C}$ are the oxygen-to-carbon and hydrogen-to-carbon ratios of the formula. Two general trends are observed in Fig. 4 for both ion polarities. First, the unique formulas in $35 \mathrm{~nm}$ particles tend to have higher OSc than the common formulas, while the unique formulas in $110 \mathrm{~nm}$ particles tend to have lower OSc than the common formulas. Second, $110 \mathrm{~nm}$ particles tend to have a greater number of unique oligomer formulas with greater than 18 carbon atoms than $35 \mathrm{~nm}$ particles, and this disparity increases with increasing number of carbon atoms. Both of these differences are consistent with the elemental composition changes in Fig. 2. Higher-OSc formulas tend to have higher $\mathrm{O} / \mathrm{C}$ elemental ratios, which favor higher $\mathrm{O} / \mathrm{C}$ in smaller particles. Formulas of higher-order oligomers tend to have lower OSc than monomers and dimers, which favor lower $\mathrm{O} / \mathrm{C}$ in larger particles.

Further insight can be gained from the ion signal intensities of each assigned molecular formula. Figure 5 shows the fraction of the total signal intensity due to higher-order oligomers (defined here as formulas with greater than 18 carbon atoms) as a function of particle size. These oligomers are produced almost exclusively by accretion chemistry in the particle phase (Barsanti and Pankow, 2005, 2006). In Fig. 5, both ion polarities show an approximate linear increase of oligomer intensity with increasing particle diameter. A linear increase is expected for a volume-limited process such as accretion chemistry relative to a surface-limited process such as condensation. Here, "volume-limited" means that the particle volume available for reaction increases linearly with

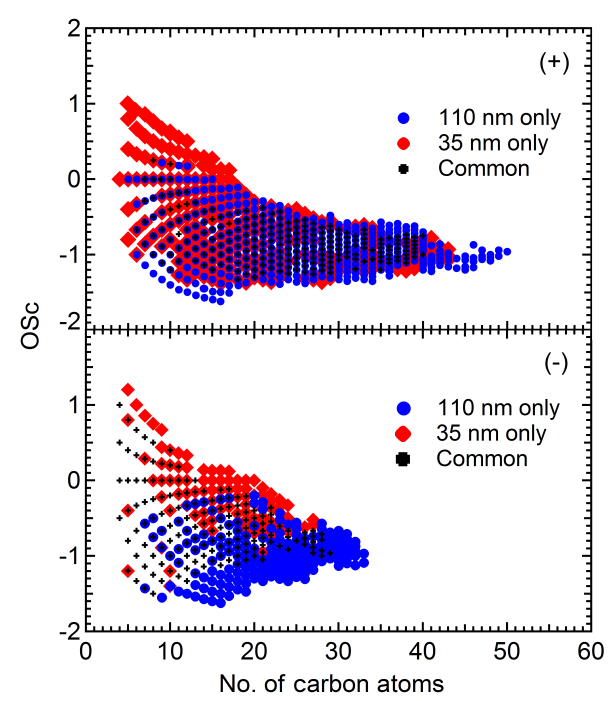

Figure 4. Carbon oxidation state (OSc) vs. number of carbon atoms for assigned molecular formulas from the positive $(+)$ and negative (-) ion mass spectra of 35 and $110 \mathrm{~nm}$ monodisperse SOA samples. Unique formulas in the $35 \mathrm{~nm}$ samples are shown in red. Unique formulas in the $110 \mathrm{~nm}$ samples are shown in blue. Formulas common to both samples are shown in black.

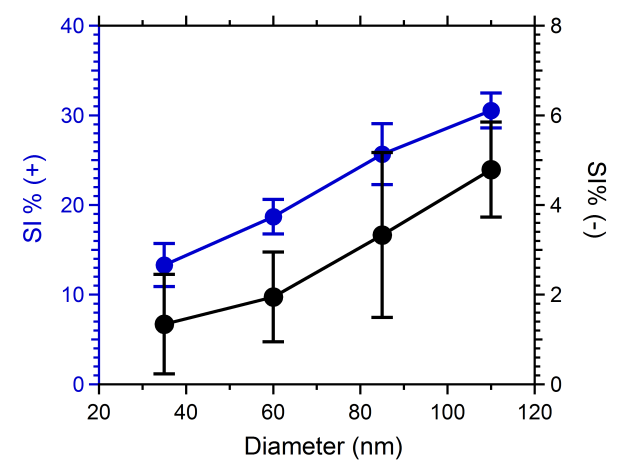

Figure 5. Percentage of total signal intensity (SI \%) in positive (+) and negative $(-)$ ion mass spectra from higher-order oligomers (molecular formulas having greater than 18 carbon atoms) vs. particle diameter. Error bars represent 1 standard deviation for the five replicate experiments.

increasing particle volume, i.e., the cube of the particle diameter. It does not preclude the possibility that processes such as phase separation or hindered diffusion within the particle cause a portion of the total particle volume to be inaccessible to this chemistry, though we note that phase separation is unlikely in such small particles (Veghte et al., 2013). Oligomerization has been considered for many years to be a significant contributor to SOA formation (Hall and Johnston, 2011; Kalberer et al., 2004; Kroll and Seinfeld, 2008; Tolocka et al., 2004; Trump and Donahue, 2014), and Fig. 5 shows through chemical measurement that this contribution strongly depends on particle size. 
The particle size dependence of oligomers reported here for $\beta$-pinene SOA is opposite that reported previously in the ultrafine size range for two other precursors, $\alpha$-cedrene and trans-3-hexene (Zhao et al., 2013, 2015). This difference is related most likely to the origin of the species involved (gas phase vs. particle phase). The molecular structure of $\alpha$-cedrene is much more conducive to the production of ELVOCs in the gas phase than $\beta$-pinene, making condensational growth more likely. In contrast, the analysis of $\beta$-pinene SOA in Fig. 5 focuses on accretion chemistry and does not include "dimer" $\left(\mathrm{C}_{10}\right.$ to $\left.\mathrm{C}_{17}\right)$ products of $\beta$-pinene ozonolysis, which may contribute to growth by a combination of condensation from the gas phase and accretion chemistry in the particle phase. The dimer products of $\beta$-pinene ozonolysis in this work show a roughly constant relative signal intensity with increasing particle size, which likely reflects the multiple sources of these species. High-molecularweight oligomers observed in the trans-3-hexene ozonolysis experiment were suggested to be formed in the gas phase by reaction of a peroxy radical with the stable Criegee intermediate, which is unlikely for either $\alpha$-cedrene or $\beta$-pinene (Zhao et al., 2015).

Figure 6 shows the intensity-weighted average OSc of all monomer formulas (carbon number $<10$ ) as a function of particle size. The average OSc for species detected in negative-ion mode is essentially independent of particle diameter, suggesting very little change in composition among these species. This dependence is suggested by the OSc (-) vs. carbon number plot in Fig. 4, where most monomer species are found to be common to both particle sizes. The lack of a composition dependence probably arises from the fact that negative-ion mode is biased toward detection of more highly oxidized species, as reported in the past by our group and others (Hall et al., 2013; Mutzel et al., 2015; Tu et al., 2016). These highly oxygenated/oxidized species are suggested to have very low volatilities, so their rates of condensation relative to each other are not expected to be size dependent - all of them will condense with similar probability when striking the particle surface.

More interesting is the plot in Fig. 6 for positive-ion mode, which shows a substantial decrease of monomer OSc with increasing particle diameter. This dependence is suggested by the OSc (+) vs. carbon number plot in Fig. 4 for positive-ion mode, where fewer molecular formulas are common between the two particle sizes and the unique formulas in $35 \mathrm{~nm}$ particles have higher OSc than the unique formulas in $110 \mathrm{~nm}$ particles. While it is tempting to interpret these data as enhanced partitioning of higher-volatility species into larger particles, this explanation is problematic. The particle sizes investigated in this work are too large for the Kelvin effect to influence molecular volatility. To the extent that partitioning reaches equilibrium, there should be no difference in the particle phase concentrations of partitioned species since the equilibrium state does not depend explicitly on particle size. Partitioning does depend on the relative volumes of the gas

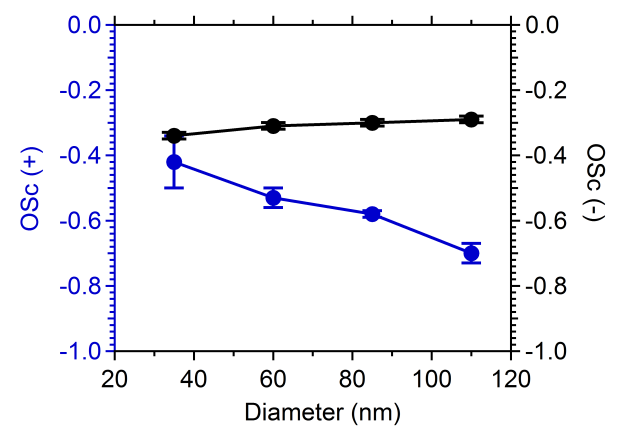

Figure 6. Average OSc vs. particle diameter for monomer species (fewer than 10 carbon atoms in the assigned formula) detected in positive $(+)$ and negative $(-)$ ion mass spectra. Error bars represent 1 standard deviation for five replicate experiments.

and particle phases for the entire system, but these volumes are fixed in the current experiments since the selection of different particle sizes was performed at the same time point in the SOA formation process.

Particle phase reactions such as accretion chemistry have the ability to increase SOA mass by transforming semivolatile monomers into non-volatile oligomers. Molecular partitioning from the gas phase to the particle phase provides a continuous source of reactant molecules to feed the reaction as it proceeds. The decreasing OSc $(+)$ of monomers with increasing particle size suggests that oligomerization is partially reversible. Larger particles have greater oligomer content relative to the total particle mass (Fig. 5), so they also have greater potential to yield decomposition products. Oligomer decomposition could be an artifact of the sample preparation and analysis steps after particle collection, or it could be an intrinsic aspect of accretion chemistry that occurs prior to particle collection and analysis. If reversibility is an intrinsic aspect of accretion chemistry, then the higher amounts of low-OSc monomers in large particles suggest that diffusion within the particle phase is hindered (Faulhaber et al., 2009; Grayson et al., 2016; Koop et al., 2011; Renbaum-Wolff et al., 2013) and/or phase separation has occurred (Laskina et al., 2015; Veghte et al., 2013; Virtanen et al., 2011; Werner et al., 2016), effectively trapping the released monomers within the particle and making them unable to re-equilibrate with the gas phase. Reversibility of the oligomerization process provides a reasonable explanation why $\beta$-pinene SOA yields are so strongly dependent on temperature and relative humidity (von Hessberg et al., 2009).

\subsection{Elemental and molecular composition of polydisperse SOA}

Additional experiments were performed to study the change in composition of polydisperse SOA samples with volumeto-surface-area ratios between 3.8 and $12.5 \mathrm{~nm}$, and compare the results to those discussed above for size-selected particles 
having a similar range of volume-to-surface-area ratios. For the aerosol generation method used in this work, the polydisperse aerosol mode diameters and volume-to-surface-area ratios increased monotonically with increasing mass loading (Table S1). Three mass loadings were investigated: 5, 240, and $2300 \mu \mathrm{g} \mathrm{m}^{-3}$ (which was also the mass loading used to study the particle size dependencies above). The results are included in Tables S1-S3. Mass spectra and plots of OSc vs. carbon number are given in Figs. S3 and S4. The mass loading trends mirror those of particle size. For both NAMS and HR-MS, the average $\mathrm{O} / \mathrm{C}$ ratio decreases with increasing mass loading. Unique molecular formulas in the low-massloading spectra generally have high OSc values, while unique molecular formulas in the high-mass-loading spectra generally have low OSc values. Oligomer ions increase in relative signal intensity with increasing mass loading. Because of the particle volume dependence of accretion reactions, high mass loadings (and their correspondingly high volume-to-surfacearea ratios) also have a higher percentage of oligomer products. A similar volume-to-surface-area ratio dependence was reported for accretion reaction products associated with polydisperse secondary aerosol produced from $\mathrm{OH}$ oxidation of cyclic siloxanes (Wu and Johnston, 2017).

A decrease in average $\mathrm{O} / \mathrm{C}$ ratio with increasing SOA mass loading has been reported previously for elemental analysis of laboratory SOA produced from related biogenic precursors (Chhabra et al., 2010; Shilling et al., 2009). The results presented here utilizing both elemental and molecular composition measurements provide a mechanistic explanation for this general observation: accretion chemistry increases in importance relative to condensation and partitioning as the particle size increases.

\section{Conclusions}

In this work, elemental and molecular analysis of sizeselected biogenic SOA particles between 35 and $110 \mathrm{~nm}$ diameter is reported. These results provide clear evidence for oligomer formation via accretion chemistry in the particle phase and show that the impact of accretion chemistry (a particle-volume-limited process) on molecular composition increases with increasing particle size. Since accretion reactions provide the opportunity to transform semivolatile monomers into non-volatile oligomers, they represent a chemical pathway to increase the aerosol yield and also potentially to increase the growth rate of ultrafine particles.

Since the ELVOC yield from $\beta$-pinene ozonolysis is much smaller than that from other biogenic SOA precursors, it is possible that accretion chemistry plays a larger role in formation of $\beta$-pinene SOA than in formation of SOA from other precursors where the likelihood of ELVOC condensation is greater. As noted in a previous study, oligomer formation in $\beta$-pinene SOA is strongly dependent on reaction condi- tions (von Hessberg et al., 2009). The impact of accretion chemistry may be greater for the laboratory SOA studied here than ambient SOA owing to different reaction conditions. In this regard, elemental analysis shows that ambient SOA is generally more highly oxidized than laboratory SOA (Aiken et al., 2008). Also, molecular analysis of ambient samples shows that oligomer ions tend to have very low signal intensities (Mentel et al., 2015), though higher oligomer signal intensities appear to be strongly correlated with CCN activity (Kourtchev et al., 2016). The results we present here illustrate the potential impact that particle phase chemistry can have on SOA formation and the particle size range where this chemistry becomes important.

Data availability. Data from this study can be obtained on request from author Peijun Tu (rebacca@udel.edu).

\section{The Supplement related to this article is available online at https://doi.org/10.5194/acp-17-7593-2017-supplement.}

Competing interests. The authors declare that they have no conflict of interest.

Acknowledgements. This research was supported by the US National Science Foundation under grant number CHE-1408455. The authors thank Andrew Horan for assistance in HR-MS analysis.

Edited by: M. Shiraiwa

Reviewed by: two anonymous referees

\section{References}

Aiken, A. C., Decarlo, P. F., Kroll, J. H., Worsnop, D. R., Huffman, J. A., Docherty, K. S., Ulbrich, I. M., Mohr, C., Kimmel, J. R., Sueper, D., Sun, Y., Zhang, Q., Trimborn, A., Northway, M., Ziemann, P. J., Canagaratna, M. R., Onasch, T. B., Alfarra, M. R., Prevot, A. S. H., Dommen, J., Duplissy, J., Metzger, A., Baltensperger, U., and Jimenez, J. L.: $\mathrm{O} / \mathrm{C}$ and $\mathrm{OM} / \mathrm{OC}$ ratios of primary, secondary, and ambient organic aerosols with high-resolution time-of-flight aerosol mass spectrometry, Environ. Sci. Technol., 42, 4478-4485, https://doi.org/10.1021/es703009q, 2008.

Barsanti, K. C. and Pankow, J. F.: Thermodynamics of the formation of atmospheric organic particulate matter by accretion reactions - 2. Dialdehydes, methylglyoxal, and diketones, Atmos. Environ., 39, 6597-6607, https://doi.org/10.1016/j.atmosenv.2005.07.056, 2005.

Barsanti, K. C. and Pankow, J. F.: Thermodynamics of the formation of atmospheric organic particulate matter by accretion reactions - Part 3: Carboxylic and dicarboxylic acids, Atmos. Environ., 40, 6676-6686, https://doi.org/10.1016/j.atmosenv.2006.03.013, 2006. 
Bianchi, F., Tröstl, J., Junninen, H., Frege, C., Henne, S., Hoyle, C.R., Molteni, U., Herrmann, E., Adamov, A., Bukowiecki, N., Chen, X., Duplissy, J., Gysel, M., Hutterli, M., Kangasluoma, J., Kontkanen, J., Kürten, A., Manninen, H. E., Münch, S., Peräkylä, O., Petäjä, T., Rondo, L., Williamson, C., Weingartner, E., Curtius, J., Worsnop, D. R., Kulmala, M., Dommen, J., and Baltensperger, U.: New particle formation in the free troposphere: A question of chemistry and timing, Science, 352, 1109-1112, https://doi.org/10.1126/science.aad5456, 2016.

Bzdek, B. R., Pennington, M. R., and Johnston, M. V.: Single particle chemical analysis of ambient ultrafine aerosol: A review, J. Aerosol Sci., 52, 109-120, https://doi.org/10.1016/j.jaerosci.2012.05.001, 2012.

Carslaw, K. S., Lee, L., Reddington, C. L., Mann, G. W., and Pringle, K. J.: The magnitude and sources of uncertainty in global aerosol, Faraday Discuss., 165, 495-512, https://doi.org/10.1039/c3fd00043e, 2013.

Chan, A. W. H., Isaacman, G., Wilson, K. R., Worton, D. R., Ruehl, C. R., Nah, T., Gentner, D. R., Dallmann, T. R., Kirchstetter, T. W., Harley, R. A., Gilman, J. B., Kuster, W. C., De Gouw, J. A., Offenberg, J. H., Kleindienst, T. E., Lin, Y. H., Rubitschun, C. L., Surratt, J. D., Hayes, P. L., Jimenez, J. L., and Goldstein, A. H.: Detailed chemical characterization of unresolved complex mixtures in atmospheric organics: Insights into emission sources, atmospheric processing, and secondary organic aerosol formation, J. Geophys. Res.-Atmos., 118, 6783-6796, https://doi.org/10.1002/jgrd.50533, 2013.

Chhabra, P. S., Flagan, R. C., and Seinfeld, J. H.: Elemental analysis of chamber organic aerosol using an aerodyne high-resolution aerosol mass spectrometer, Atmos. Chem. Phys., 10, 4111-4131, https://doi.org/10.5194/acp-10-4111-2010, 2010.

Daumit, K. E., Kessler, S. H., and Kroll, J. H.: Average chemical properties and potential formation pathways of highly oxidized organic aerosol, Faraday Discuss., 165, 181-202, https://doi.org/10.1039/C3FD00045A, 2013.

Ehn, M., Thornton, J. A., Kleist, E., Sipilä, M., Junninen, H., Pullinen, I., Springer, M., Rubach, F., Tillmann, R., Lee, B., Lopez-Hilfiker, F., Andres, S., Acir, I.-H., Rissanen, M., Jokinen, T., Schobesberger, S., Kangasluoma, J., Kontkanen, J., Nieminen, T., Kurtén, T., Nielsen, L. B., Jørgensen, S., Kjaergaard, H. G., Canagaratna, M., Maso, M. D., Berndt, T., Petäjä, T., Wahner, A., Kerminen, V.-M., Kulmala, M., Worsnop, D. R., Wildt, J., and Mentel, T. F.: A large source of lowvolatility secondary organic aerosol, Nature, 506, 476-479, https://doi.org/10.1038/nature13032, 2014.

Faulhaber, A. E., Thomas, B. M., Jimenez, J. L., Jayne, J. T., Worsnop, D. R., and Ziemann, P. J.: Characterization of a thermodenuder-particle beam mass spectrometer system for the study of organic aerosol volatility and composition, Atmos. Meas. Tech., 2, 15-31, https://doi.org/10.5194/amt-2-15-2009, 2009.

Gao, S., Keywood, M., Ng, N. L., Surratt, J., Varutbangkul, V., Bahreini, R., Flagan, R. C., and Seinfeld, J. H.: Lowmolecular-weight and oligomeric components in secondary organic aerosol from the ozonolysis of cycloalkenes and $\alpha$-pinene, J. Phys. Chem. A, 108, 10147-10164, https://doi.org/10.1021/jp047466e, 2004.
Goldstein, A. H. and Galbally, I. E.: Known and unexplored organic constituents in the earth's atmosphere, Environ. Sci. Technol., 41, 1514-1521, https://doi.org/10.1021/es072476p, 2007.

Grayson, J. W., Zhang, Y., Mutzel, A., Renbaum-Wolff, L., Böge, O., Kamal, S., Herrmann, H., Martin, S. T., and Bertram, A. K.: Effect of varying experimental conditions on the viscosity of $\alpha$-pinene derived secondary organic material, Atmos. Chem. Phys., 16, 6027-6040, https://doi.org/10.5194/acp-166027-2016, 2016.

Hall, W. A. and Johnston, M. V.: Oligomer Content of $\alpha$-Pinene Secondary Organic Aerosol, Aerosol Sci. Technol., 45, 37-45, https://doi.org/10.1080/02786826.2010.517580, 2011.

Hall IV, W. A. and Johnston, M. V.: Oligomer formation pathways in secondary organic aerosol from MS and MS/MS measurements with high mass accuracy and resolving power, J. Am. Soc. Mass Spectrom., 23, 1097-1108, https://doi.org/10.1007/s13361-012-0362-6, 2012.

Hall, W. A., Pennington, M. R., and Johnston, M. V.: Molecular transformations accompanying the aging of laboratory secondary organic aerosol, Environ. Sci. Technol., 47, 2230-2237, https://doi.org/10.1021/es303891q, 2013.

Hallquist, M., Wenger, J. C., Baltensperger, U., Rudich, Y., Simpson, D., Claeys, M., Dommen, J., Donahue, N. M., George, C., Goldstein, A. H., Hamilton, J. F., Herrmann, H., Hoffmann, T., Iinuma, Y., Jang, M., Jenkin, M. E., Jimenez, J. L., Kiendler-Scharr, A., Maenhaut, W., McFiggans, G., Mentel, Th. F., Monod, A., Prévôt, A. S. H., Seinfeld, J. H., Surratt, J. D., Szmigielski, R., and Wildt, J.: The formation, properties and impact of secondary organic aerosol: current and emerging issues, Atmos. Chem. Phys., 9, 5155-5236, https://doi.org/10.5194/acp9-5155-2009, 2009.

Hering, S. V. and Stolzenburg, M. R.: A Method for Particle Size Amplification by Water Condensation in a Laminar, Thermally Diffusive Flow, Aerosol Sci. Tech., 39, 428-436, https://doi.org/10.1080/027868290953416, 2005.

Herzsprung, P., Hertkorn, N., von Tümpling, W., Harir, M., Friese, K., and Schmitt-Kopplin, P.: Understanding molecular formula assignment of Fourier transform ion cyclotron resonance mass spectrometry data of natural organic matter from a chemical point of view, Anal. Bioanal. Chem., 406, 7977-7987, https://doi.org/10.1007/s00216-014-8249-y, 2014.

Jaoui, M. and Kamens, R. M.: Gaseous and particulate oxidation products analysis of a mixture of $\alpha$-pinene $+\beta$-pinene $/ \mathrm{O}_{3} /$ air in the absence of light and $\alpha$-pinene $+\beta$-pinene $/ \mathrm{NO}_{x} /$ air in the presence of natural sunlight, J. Atmos. Chem., 44, 259-297, https://doi.org/10.1023/A:1022977427523, 2003.

Jimenez, J. L., Canagaratna, M. R., Donahue, N. M., Prevot, a. S. H., Zhang, Q., Kroll, J. H., DeCarlo, P. F., Allan, J. D., Coe, H., Ng, N. L., Aiken, a. C., Docherty, K. S., Ulbrich, I. M., Grieshop, A. P., Robinson, a. L., Duplissy, J., Smith, J. D., Wilson, K. R., Lanz, V. a., Hueglin, C., Sun, Y. L., Tian, J., Laaksonen, A., Raatikainen, T., Rautiainen, J., Vaattovaara, P., Ehn, M., Kulmala, M., Tomlinson, J. M., Collins, D. R., Cubison, M J., Dunlea, J., Huffman, J. A., Onasch, T. B., Alfarra, M. R., Williams, P. I., Bower, K., Kondo, Y., Schneider, J., Drewnick, F., Borrmann, S., Weimer, S., Demerjian, K., Salcedo, D., Cottrell, L., Griffin, R., Takami, a., Miyoshi, T., Hatakeyama, S., Shimono, A., Sun, J. Y., Zhang, Y. M., Dzepina, K., Kimmel, J. R., Sueper, D., Jayne, J. T., Herndon, S. C., Trimborn, a. 
M., Williams, L. R., Wood, E. C., Middlebrook, A. M., Kolb, C. E., Baltensperger, U., and Worsnop, D. R.: Evolution of Organic Aerosols in the Atmosphere, Science, 326, 1525-1529, https://doi.org/10.1126/science.1180353, 2009.

Kalberer, M., Paulsen, D., Sax, M., Steinbacher, M., Dommen, J., Prevot, a S. H., Fisseha, R., Weingartner, E., Frankevich, V., Zenobi, R., and Baltensperger, U.: Identification of polymers as major components of atmospheric organic aerosols, Science, 303, 1659-1662, https://doi.org/10.1126/science.1092185, 2004.

Kanakidou, M., Seinfeld, J. H., Pandis, S. N., Barnes, I., Dentener, F. J., Facchini, M. C., Van Dingenen, R., Ervens, B., Nenes, A., Nielsen, C. J., Swietlicki, E., Putaud, J. P., Balkanski, Y., Fuzzi, S., Horth, J., Moortgat, G. K., Winterhalter, R., Myhre, C. E. L., Tsigaridis, K., Vignati, E., Stephanou, E. G., and Wilson, J.: Organic aerosol and global climate modelling: a review, Atmos. Chem. Phys., 5, 1053-1123, https://doi.org/10.5194/acp-5-10532005, 2005.

Kidd, C., Perraud, V., and Finlayson-Pitts, B. J.: New insights into secondary organic aerosol from the ozonolysis of $\alpha$-pinene from combined infrared spectroscopy and mass spectrometry measurements, Phys. Chem. Chem. Phys., 16, 22706-22716, https://doi.org/10.1039/c4cp03405h, 2014.

Klems, J. P. and Johnston, M. V.: Origin and impact of particle-toparticle variations in composition measurements with the nanoaerosol mass spectrometer, Anal. Bioanal. Chem., 405, 69957003, https://doi.org/10.1007/s00216-013-6800-x, 2013.

Koop, T., Bookhold, J., Shiraiwa, M., and Pöschl, U.: Glass transition and phase state of organic compounds: dependency on molecular properties and implications for secondary organic aerosols in the atmosphere, Phys. Chem. Chem. Phys., 13, 19238, https://doi.org/10.1039/c1cp22617g, 2011.

Kourtchev, I., Giorio, C., Manninen, A., Wilson, E., Mahon, B., Aalto, J., Kajos, M., Venables, D., Ruuskanen, T., Levula, J., Loponen, M., Connors, S., Harris, N., Zhao, D., Kiendler-Scharr, A., Mentel, T., Rudich, Y., Hallquist, M., Doussin, J.-F., Maenhaut, W., Bäck, J., Petäjä, T., Wenger, J., Kulmala, M., and Kalberer, M.: Enhanced Volatile Organic Compounds emissions and organic aerosol mass increase the oligomer content of atmospheric aerosols, Sci. Rep., 6, 35038, https://doi.org/10.1038/srep35038, 2016.

Kroll, J. H. and Seinfeld, J. H.: Chemistry of secondary organic aerosol: Formation and evolution of low-volatility organics in the atmosphere, Atmos. Environ., 42, 3593-3624, https://doi.org/10.1016/j.atmosenv.2008.01.003, 2008.

Kroll, J. H., Donahue, N. M., Jimenez, J. L., Kessler, S. H., Canagaratna, M. R., Wilson, K. R., Altieri, K. E., Mazzoleni, L. R., Wozniak, A. S., Bluhm, H., Mysak, E. R., Smith, J. D., Kolb, C. E., and Worsnop, D. R.: Carbon oxidation state as a metric for describing the chemistry of atmospheric organic aerosol, Nat. Chem., 3, 133-139, https://doi.org/10.1038/nchem.948, 2011.

Laskina, O., Morris, H. S., Grandquist, J. R., Qin, Z., Stone, E. A., Tivanski, A. V., and Grassian, V. H.: Size Matters in the water uptake and hygroscopic growth of atmospherically relevant multicomponent aerosol particles, J. Phys. Chem. A, 119, 4489-4497, https://doi.org/10.1021/jp510268p, 2015.

Mentel, T. F., Springer, M., Ehn, M., Kleist, E., Pullinen, I., Kurtén, T., Rissanen, M., Wahner, A., and Wildt, J.: Formation of highly oxidized multifunctional compounds: autoxidation of peroxy radicals formed in the ozonolysis of alkenes - deduced from structure-product relationships, Atmos. Chem. Phys., 15, 67456765, https://doi.org/10.5194/acp-15-6745-2015, 2015.

Mutzel, A., Poulain, L., Berndt, T., Iinuma, Y., Rodigast, M., Böge, O., Richters, S., Spindler, G., Sipilä, M., Jokinen, T., Kulmala, M., and Herrmann, H.: Highly Oxidized Multifunctional Organic Compounds Observed in Tropospheric Particles: A Field and Laboratory Study, Environ. Sci. Technol., 49, 7754-7761, https://doi.org/10.1021/acs.est.5b00885, 2015.

Myhre, G., Shindell, D., Bréon, F.-M., Collins, W., Fuglestvedt, J., Huang, J., Koch, D., Lamarque, J.-F., Lee, D., Mendoza, B., Nakajima, T., Robock, A., Stephens, G., Takemura, T. and Zhang, H.: Anthropogenic and Natural Radiative Forcing, in: Climate Change 2013: The Physical Science Basis. Contribution of Working Group I to the Fifth Assessment Report of the Intergovernmental Panel on Climate Change, edited by: Stocker, T. F., Qin, D., Plattner, G.-K., Tignor, M., Allen, S. K., Boschung, J., Nauels, A., Xia, Y., Bex, V., and Midgley, P. M., Cambridge University Press, Cambridge, United Kingdom and New York, NY, USA, 659-740, https://doi.org/10.1017/CBO9781107415324.018, 2013.

Ng, N. L., Canagaratna, M. R., Zhang, Q., Jimenez, J. L., Tian, J., Ulbrich, I. M., Kroll, J. H., Docherty, K. S., Chhabra, P. S., Bahreini, R., Murphy, S. M., Seinfeld, J. H., Hildebrandt, L., Donahue, N. M., Decarlo, P. F., Lanz, V. A., Prévôt, A. S. H., Dinar, E., Rudich, Y., and Worsnop, D. R.: Organic aerosol components observed in Northern Hemispheric datasets from Aerosol Mass Spectrometry, Atmos. Chem. Phys., 10, 46254641, https://doi.org/10.5194/acp-10-4625-2010, 2010.

Pankow, J. F.: An absorption model of gas/particle partitioning of organic compounds in the atmosphere, Atmos. Environ., 28, 185-188, https://doi.org/10.1016/1352-2310(94)90093-0, 1994.

Park, J. Y., McMurry, P. H., and Park, K.: Production of Residue-Free Nanoparticles by Atomization of Aqueous Solutions, Aerosol Sci. Tech., 46, 354-360, https://doi.org/10.1080/02786826.2011.631614, 2012.

Pennington, M. R. and Johnston, M. V.: Trapping charged nanoparticles in the nano aerosol mass spectrometer (NAMS), Int. J. Mass Spectrom., 311, 64-71, https://doi.org/10.1016/j.ijms.2011.12.011, 2012.

Perraud, V., Bruns, E., Ezell, M. J., Johnson, S. N., Yu, Y., Alexander, M. L., Zelenyuk, A., Imre, D., Chang, W. L., Dabdub, D., Pankow, J. F., and Finlayson-Pitts, B. J.: Nonequilibrium atmospheric secondary organic aerosol formation and growth, P. Natl. Acad. Sci. USA, 109, 2836-2841, https://doi.org/10.1073/pnas.1119909109, 2012.

Phungsai, P., Kurisu, F., Kasuga, I., and Furumai, H.: Molecular characterization of low molecular weight dissolved organic matter in water reclamation processes using Orbitrap mass spectrometry, Water Res., 100, 526-536, https://doi.org/10.1016/j.watres.2016.05.047, 2016.

Putman, A. L., Offenberg, J. H., Fisseha, R., Kundu, S., Rahn, T. A., and Mazzoleni, L. R.: Ultrahigh-resolution FT-ICR mass spectrometry characterization of alphapinene ozonolysis SOA, Atmos. Environ., 46, 164-172, https://doi.org/10.1016/j.atmosenv.2011.10.003, 2012.

Renbaum-Wolff, L., Grayson, J. W., Bateman, A. P., Kuwata, M., Sellier, M., Murray, B. J., Shilling, J. E., Martin, S. T., and Bertram, A. K.: Viscosity of $\alpha$-pinene secondary organic material and implications for particle growth 
and reactivity, P. Natl. Acad. Sci. USA, 110, 8014-8019, https://doi.org/10.1073/pnas.1219548110, 2013.

Shilling, J. E., Chen, Q., King, S. M., Rosenoern, T., Kroll, J. H., Worsnop, D. R., Decarlo, P. F., Aiken, A. C., Sueper, D., Jimenez, J. L., and Martin, S. T.: Loading-dependent elemental composition of $\alpha$-pinene SOA particles, Atmos. Chem. Phys., 9, 771782, https://doi.org/10.5194/acp-9-771-2009, 2009.

Shiraiwa, M., Yee, L. D., Schilling, K. A., Loza, C. L., Craven, J. S., Zuend, A., Ziemann, P. J., and Seinfeld, J. H.: Size distribution dynamics reveal particle-phase chemistry in organic aerosol formation, P. Natl. Acad. Sci. USA, 110, 11746-11750, https://doi.org/10.1073/pnas.1307501110, 2013.

Stabile, L., Trassierra, C. V., Dell'Agli, G., and Buonanno, G.: Ultrafine particle generation through atomization technique: The influence of the solution, Aerosol Air Qual. Res., 13, 1667-1677, https://doi.org/10.4209/aaqr.2013.03.0085, 2013.

Tolocka, M. P., Jang, M., Ginter, J. M., Cox, F. J., Kamens, R. M., and Johnston, M. V.: Formation of Oligomers in Secondary Organic Aerosol, Environ. Sci. Technol., 38, 1428-1434, https://doi.org/10.1021/es035030r, 2004.

Trump, E. R. and Donahue, N. M.: Oligomer formation within secondary organic aerosols: equilibrium and dynamic considerations, Atmos. Chem. Phys., 14, 3691-3701, https://doi.org/10.5194/acp-14-3691-2014, 2014.

Tu, P., Hall, W. A., and Johnston, M. V.: Characterization of Highly Oxidized Molecules in Fresh and Aged Biogenic Secondary Organic Aerosol, Anal. Chem., 88, 4495-4501, https://doi.org/10.1021/acs.analchem.6b00378, 2016.

Veghte, D. P., Altaf, M. B., and Freedman, M. A.: Size dependence of the structure of organic aerosol, J. Am. Chem. Soc., 135, 16046-16049, https://doi.org/10.1021/ja408903g, 2013.

Virtanen, A., Kannosto, J., Kuuluvainen, H., Arffman, A., Joutsensaari, J., Saukko, E., Hao, L., Yli-Pirilä, P., Tiitta, P., Holopainen, J. K., Keskinen, J., Worsnop, D. R., Smith, J. N., and Laaksonen, A.: Bounce behavior of freshly nucleated biogenic secondary organic aerosol particles, Atmos. Chem. Phys., 11, 8759-8766, https://doi.org/10.5194/acp-11-8759-2011, 2011.

von Hessberg, C., von Hessberg, P., Pöschl, U., Bilde, M., Nielsen, O. J., and Moortgat, G. K.: Temperature and humidity dependence of secondary organic aerosol yield from the ozonolysis of $\beta$-pinene, Atmos. Chem. Phys., 9, 3583-3599, https://doi.org/10.5194/acp-9-3583-2009, 2009.
Wang, S. and Johnston, M. V.: Airborne nanoparticle characterization with a digital ion trap-reflectron time of flight mass spectrometer, Int. J. Mass Spectrom., 258, 50-57, https://doi.org/10.1016/j.ijms.2006.07.001, 2006.

Wang, S., Zordan, C. A., and Johnston, M. V: Chemical Characterization of Individual, Airborne Sub-10 nm Particles and Molecules, Anal. Chem., 78, 1750-1754, https://doi.org/10.1021/ac0522431, 2006.

Werner, J., Dalirian, M., Walz, M.-M., Ekholm, V., Wideqvist, U., Lowe, S. J., Öhrwall, G., Persson, I., Riipinen, I., and Bjorneholm, O.: Surface partitioning in organic-inorganic mixtures contributes to the size-dependence of the phase-state of atmospheric nanoparticles, Environ. Sci. Technol., 50, 7434-7442, https://doi.org/10.1021/acs.est.6b00789, 2016.

Winkler, P. M., Ortega, J., Karl, T., Cappellin, L., Friedli, H. R., Barsanti, K., McMurry, P. H., and Smith, J. N.: Identification of the biogenic compounds responsible for sizedependent nanoparticle growth, Geophys. Res. Lett., 39, 1-6, https://doi.org/10.1029/2012GL053253, 2012.

$\mathrm{Wu}$, Y. and Johnston, M. V.: Aerosol Formation from OH Oxidation of the Volatile Cyclic Methyl Siloxane (cVMS) Decamethylcyclopentasiloxane, Environ. Sci. Technol., 51, 44454451, https://doi.org/10.1021/acs.est.7b00655, 2017.

Zhang, R., Khalizov, A., Wang, L., Hu, M., and Xu, W.: Nucleation and growth of nanoparticles in the atmosphere, Chem. Rev., 112, 1957-2011, https://doi.org/10.1021/cr2001756, 2012.

Zhao, J., Ortega, J., Chen, M., McMurry, P. H., and Smith, J. N.: Dependence of particle nucleation and growth on high-molecularweight gas-phase products during ozonolysis of $\alpha$-pinene, Atmos. Chem. Phys., 13, 7631-7644, https://doi.org/10.5194/acp13-7631-2013, 2013.

Zhao, Y., Wingen, L. M., Perraud, V., Greaves, J., and FinlaysonPitts, B. J.: Role of the reaction of stabilized Criegee intermediates with peroxy radicals in particle formation and growth in air, Phys. Chem. Chem. Phys., 17, 12500-12514, https://doi.org/10.1039/C5CP01171J, 2015.

Zordan, C. A., Pennington, M. R., and Johnston, M. V.: Elemental composition of nanoparticles with the nano aerosol mass spectrometer, Anal. Chem., 82, 8034-8038, https://doi.org/10.1021/ac101700q, 2010. 